\title{
Psychological and Behavioral Indicators in the Forensic Assessment of Child Sexual Abuse
}

\author{
Luiziana Souto Schaefer ${ }^{*}, 1,2$ \\ Orcid.org/0000-0002-7349-6532 \\ Alice Einloft Brunnet ${ }^{1,4}$ \\ Orcid.org/0000-0001-5290-1343 \\ Beatriz de Oliveira Meneguelo Lobo ${ }^{3}$ \\ Orcid.org/0000-0001-8774-2012 \\ Janaína Castro Núñez Carvalho ${ }^{1}$ \\ Orcid.org/0000-0001-5979-339X \\ Christian Haag Kristensen ${ }^{1}$ \\ Orcid.org/0000-0002-8273-2146
}

\begin{abstract}
${ }^{1}$ Pontificia Universidade Católica do Rio Grande do Sul, Porto Alegre, RS, Brasil ${ }^{2}$ Instituto-Geral de Perícias do Rio Grande do Sul, Porto Alegre, RS, Brasil

${ }^{3}$ Centro Universitário Ritter dos Reis, Porto Alegre, RS, Brasil

${ }^{4}$ Université de Bourgogne Franche-Comté, Dijon, France
\end{abstract}

\begin{abstract}
This study evaluated the discriminative ability of behavioral and psychological indicators often associated with child sexual abuse. The sample consisted of 79 children of both genders, $63.3 \%$ being female $(n=50)$, aged between 8 and 12 years $(M=9.92, S D=1.45)$. Participants were assigned to three groups: Sexual abuse $(n=34)$, Maltreatment with no history of sexual abuse $(n=14)$ and Clinical symptoms with no history of abuse or other traumatic events $(n=31)$. Assessment measures were administered with the legal guardians and with the children. A multinomial logistic regression analysis was conducted aiming to identify factors for differentiation of the groups. The TSCC Sexual concerns variable emerged as significant in differentiating the Sexual abuse group from both the Maltreatment and Clinical symptoms groups. The model showed overall predictive ability to accurately classify $69.6 \%$ of the cases. The investigation of this variable should be included, among other indicators, in forensic procedures for children with suspected sexual abuse. Based on the results, it becomes clear that caution is required in establishing causal relationships between behavioral or psychological manifestations and the hypothesis of child sexual abuse.
\end{abstract}

Keywords: Child sexual abuse, behavioral symptoms, psychic symptoms.

* Mailing address: Instituto-Geral de Perícias do Rio Grande do Sul, Departamento Médico-Legal, Avenida Ipiranga, 1807, Praia de Belas, Porto Alegre, RS, Brasil 90160093. Phone: (51) 32882654 E-mail: luiziana. schaefer@gmail.com, brunnetalice@gmail.com, beatrizlobo.m@gmail.com, janainanunez@gmail.com and christian.kristensen@pucrs.br

Financing: Coordenação de Aperfeiçoamento de Pessoal de Nível Superior; Pontifícia Universidade Católica do Rio Grande do Sul; Instituto-Geral de Perícias do Rio Grande do Sul 


\section{Indicadores Psicológicos e Comportamentais na Perícia do Abuso Sexual Infantil}

\section{Resumo}

Este estudo avaliou a capacidade discriminante de indicadores psicológicos e comportamentais frequentemente associados ao abuso sexual infantil. A amostra foi constituída por 79 crianças, de ambos os sexos, sendo 63,3\% do sexo feminino $(n=50)$, com idades entre oito e 12 anos $(M=9,92 ; D P=1,45)$. Os participantes foram distribuídos em três grupos: Abuso sexual $(n=34)$, Maus-tratos sem histórico de abuso sexual $(n=14)$ e Sintomas clínicos sem histórico de maus-tratos $(n=31)$. Foram administrados instrumentos com os responsáveis e com as crianças. Para identificar os fatores que diferenciavam os grupos, foi realizada a Análise de regressão logística multinominal. A variável Preocupações sexuais foi significativa para diferenciar o grupo Abuso sexual dos outros dois grupos. O modelo apresentou capacidade preditiva geral de classificar corretamente $69,6 \%$ dos casos. Sugere-se que a investigação dessa variável seja incluída, entre outros indicadores, nos procedimentos periciais de crianças com suspeita de abuso sexual. Com base nos resultados obtidos, fica evidente que é necessário cautela no estabelecimento de associações causais entre manifestações comportamentais ou psicológicas e a hipótese de abuso sexual em crianças.

Palavras-chave: Abuso sexual na infância, sintomas comportamentais, sintomas psíquicos.

\section{Indicadores Psicológicos y Conductuales en la Pericia del Abuso Sexual Infantil}

\section{Resumen}

Este estudio evaluó la capacidad discriminante de indicadores psicológicos y conductuales frecuentemente asociados al abuso sexual infantil. La muestra fue constituida por 79 niños, de ambos sexos, siendo $63,3 \%$ do sexo femenino $(n=50)$, com edades entre ocho y 12 años $(M=9,92 ; D E=1,45)$. Los participantes fueron distribuidos en tres grupos: Abuso sexual $(n=34)$, Malos tratos sin antecedentes de abuso sexual $(n=14)$ y Sintomas clínicos sin antecedentes de maltrato $(n=31)$. Se han administrados instrumentos con los responsables y los niños. Para identificar los factores que diferenciaban a los grupos, se realizó el Análisis de regresión logística multinominal. La variable Preocupaciones sexuales apareció como significativa para diferenciar el grupo Abuso sexual de los otros dos grupos. El modelo presentó la capacidad preditiva general de clasificar correctamente $69,6 \%$ de los casos. Se sugerie la inclusión de esta variable, entre otros indicadores, en la evaluación del abuso sexual infantil. En base a los resultados obtenidos, es evidente que es necesario cautela en el establecimiento de asociaciones causales entre manifestaciones comportamentales o psicológicas y la hipótesis de abuso sexual infantil.

Palabras clave: Abuso sexual infantil, síntomas conductuales, síntomas psíquicos.

Child sexual abuse, as a public health and safety social problem, presents a challenge in terms of evaluation, intervention and prevention. It is defined as any contact or interaction between a child or adolescent and someone in a more advanced stage of psychosexual development that uses the victim for sexual gratification (World Health Organization [WHO], 2002).
Child sexual abuse has its own dynamics, often characterized by secrets, threats, withdrawals and lack of eyewitnesses, among other aspects, especially in intra-familial cases (Peixoto, 2012). These characteristics may hinder disclosure by the victim, affecting the correct confirmation of sexual abuse and, therefore, the estimation of its actual prevalence. 
In a meta-analysis, a total prevalence of $11.8 \%$ of sexual abuse in childhood was found, with a prevalence of $18.0 \%$ among females and $7.6 \%$ among males (Stoltenborgh, van IJzendoorn, Euser, \& Bakermans-Kranenburg, 2011). Regarding national data, in 2007 and 2016, 37,000 cases of sexual violence involving victims aged 0-18 years were received by Disque 100 (Portal Governo do Brasil, 2017). It should be mentioned that in Brazil, there is still no reliable data on the prevalence of sexual abuse, therefore these records probably do not represent the reality of cases reported in the country.

Sexually abused children tend to present more clinical symptomatology than those who have not been through this experience (Paolucci, Genuis, \& Violato, 2001). For example, sexual abuse has been associated with both externalizing symptoms (delinquent behavior and aggressiveness) and internalizing symptoms (depression, anxiety, isolation, attention difficulties and somatic complaints; van den Heuvel \& Seedat, 2013). At the same time, there is no single symptom that exclusively characterizes victims, and approximately one-third of the children who have experienced sexual abuse do not present any symptoms (Kendall-Tackett, Williams, \& Finkelhor, 1993). In the study by Kendall-Tackett et al. (1993), two clusters of symptoms were identified as the most reliable to characterize child victims of sexual abuse: sexualized behaviors and symptoms related to Posttraumatic Stress Disorder (PTSD). In general, studies indicate that between one-third and one-half of all child victims of sexual abuse present significant clinical posttraumatic symptoms (Collin-Vézina, Daigneault, \& Hebert, 2013).

Although there is no specific syndrome that characterizes the victims (Paolucci et al., 2001), the consequences of sexual abuse range from minimal effects to more serious problems, with social, emotional and/or psychiatric repercussions (Habigzang, Borges, Dell'Aglio, \& Koller, 2010; Kendall-Tackett et al., 1993; Paolucci et al., 2001; Wherry, Baldwin, Junco, \& Floyd, 2013). Specifically, inappropriate sexualized behaviors (wanting to touch other people's genitals, showing interest and advanced sexual knowledge for the age, masturbating frequently and publicly, among others) and sexual concerns (sexual thoughts, atypical feelings for the developmental phase of the child or occurring at a higher than expected frequency, sexual conflicts, negative responses to sexual stimuli, and fear of being sexually exploited) are some of the factors most directly referred to as suggestive of sexual abuse (Briere, 1996; Friedrich et al., 2001; Friedrich et al., 1992; Friedrich, Jaworski, Huxsahl, \& Bengtson, 1997).

In the forensic context, one of the major challenges faced by professionals is the identification of sexual abuse when there is no physical or biological evidence, which accounts for the majority of cases referred for medical forensic assessments (Joki-Erkkila, Niemi, \& Ellonen, 2014). In this context where the absence of physical and biological vestiges does not necessarily imply that sexual abuse has not occurred, complementary evaluation resources are indispensable (Peixoto, 2012; Ribeiro \& Peixoto, 2013).

The forensic psychological assessment has acquired a preponderant role as an investigative resource in cases of suspected sexual abuse (Gava, Pelisoli, \& Dell'Aglio, 2013; Schaefer, Rossetto, \& Kristensen, 2012). However, caution is needed in the performance of this evaluation because, in the psychological field, there is no single indicator that determines whether a child has been sexually abused (Pelisoli, Dell'Aglio, \& Herman, 2016). Therefore, comprehensive analyses are the most indicated (Everson \& Faller, 2012; Schaefer et al., 2012).

A review of the literature identified a growing concern regarding the use of strategies for the evaluation of sexual abuse, especially in the forensic context (Everson \& Faller, 2012; Gava et al., 2013). Historically, behavioral and psychological indicators used in clinical evaluations have also been applied in the forensic area. Such criteria, often used indiscriminately, led to other factors in the history and life context of the person being examined that might have triggered and/or contributed to the development of the symptomatology being disregarded (Gava et al., 2013). Therefore, such evaluation strategies have been rigorously questioned, with research- 
ers in the field investing in the elaboration of evaluation techniques and procedures with less controversial predictive values (Peixoto, 2012).

Efforts have been observed in the development of investigative protocols for collecting and evaluating reports of children, as this is often the only evidence (Peixoto, 2012; Peixoto et al., 2017). Although there is a consensus regarding the use of forensic interviews as a central element, many researchers also maintain that the use of other indicators and objective evaluation criteria cannot be ignored in this context (Everson \& Faller, 2012). In addition, as already mentioned, there is evidence of the psychic, behavioral, psychopathological and neurobiological consequences in victims of sexual abuse, with repercussions even in adulthood (Irigaray et al., 2013).

The present study was proposed considering the premise that the evaluation of sexual abuse in the forensic context should be performed in an integrated and comprehensive manner, including not only the interview and evaluation of the report of the child, but also objective indicators that are valid for this context and for this population. Thus, the main aim of this study was to evaluate psychological and behavioral indicators in the forensic assessment of children with suspected sexual abuse. Specifically, it was sought to assess the discriminative ability of the following variables: sexualized behaviors, posttraumatic cognitions, externalizing and internalizing symptoms, posttraumatic stress symptoms, depression, anxiety, dissociation, anger and sexual concerns.

\section{Method}

\section{Participants}

A total of 98 children recruited from the mental health services of the city of Porto Alegre and the forensic assessment service of the state of Rio Grande do Sul, Brazil, participated in the study. The exclusion criteria used were: (a) the presence of psychotic symptoms, evaluated through the Child Behavior Checklist (CBCL), (b) an indication of intellectual deficit, obtained through the $<5$ percentile in the Raven
Progressive Matrix Test, and (c) invalidation of the Trauma Symptom Checklist for Children (TSCC, scores $t>=70$ on the under-response scale and scores $t>=90$ on the hyper-response scale). Nineteen participants were excluded from the study: one presented psychotic symptoms, four presented indications of intellectual deficit, and 14 invalidated the TSCC (two children would have overestimated the symptoms and 12 children would have underestimated the symptoms).

The final sample consisted of 79 children, of both sexes, $63.3 \%$ female $(n=50)$, aged 8 to 12 years $(M=9.92, S D=1.45)$. The majority of the children $(88.6 \%, n=70)$ studied in public schools, $94.9 \%(n=75)$ had at least one sibling $(M=2.28, S D=1.5), 23.1(n=18)$ had repeated a school grade, $57.7 \%(n=45)$ had separated parents and $67.1 \%(n=53)$ belonged to economic class $\mathrm{C}$ or $\mathrm{D}$, according to the economic classification criterion of Brazil (Brazilian Association of Research Companies, 2015).

Participants were divided into three groups according to the criteria described below. Children with sexual abuse confirmed through physical or psychological forensic assessment, both performed by the official forensic assessment service of Rio Grande do Sul state, were allocated to the Sexual abuse group $(n=34)$. Of these, $41.2 \%(n=14)$ also experienced at least one other form of maltreatment. Children who had no official complaint or extra-official suspicion of sexual abuse (as investigated at the time of data collection by the investigators of this study in the semi-structured interview with those responsible and with the child), but met the criteria for experiencing maltreatment and/ or domestic violence, as defined by the WHO (2002), were included in the Maltreatment without a history of sexual abuse group $(n=14)$. Of these, $42.8 \%(n=6)$ experienced more than one form of maltreatment, and among those that had experience a single type, $21.4 \%(n=3)$ suffered neglect, $14.3 \%(n=2)$ experienced physical abuse, $14.3 \%(n=2)$ experienced domestic violence and $7.1 \%(n=1)$ experienced emotional abuse. Participants with clinical symptoms evaluated through the CBCL and without any his- 
tory of maltreatment or other traumatic events (as investigated in the semi-structured interview with the caregivers and with the child) were allocated to the Clinical symptoms without a history of traumatic events group $(n=31)$. The history of sexual abuse and other maltreatment was obtained by the researchers of this study through a semi-structured interview with the parents and through the report of the child.

\section{Instruments}

Instruments Answered by the LegalGuardians: Semi-Structured Interview with the Legal Guardians: interview designed exclusively for this study, being a semi-structured interview carried out individually with those responsible, including questions about gender, age, schooling, socioeconomic status and health conditions of the participants. The exposure of the child to maltreatment, as defined by the World Health Organization (WHO, 2002), was investigated, as well as exposure to other traumatic experiences, as defined by the DSM-5 (American Psychiatric Association, 2014), in which the individual was exposed to a concrete episode or threat of death, serious injury or sexual violence, whether directly, indirectly or as a witness.

Child Behavior Checklist (CBCL, Achenbach, 1991, Brazilian version by Bordin, Mari, \& Caeiro, 1995): inventory answered by the guardians in relation to behaviors of the children, aiming to identify behavioral and emotional aspects, as well as possible psychopathological disorders, in children between 6 and 18 years of age. In all the scales of the CBCL, the symptoms of the child are classified as clinical, borderline or nonclinical, according to Achenbach's normative sample of pairs $(1991,2001)$.

Child Sexual Behavior Inventory (CSBI, Friedrich et al., 1992, Brazilian version by Miele \& Arteche, 2017): 35 item questionnaire to be answered by the guardians. This assesses the frequency of specific sexualized behaviors, covering nine domains: Interpersonal Boundaries, Sexual Anxiety, Exhibitionism, Sexual Intrusiveness, Gender Role Behavior, Sexual Knowledge, Self-Stimulation, Voyeuristic Behavior, and Sexual Interest. The instrument was originally designed and validated for the evaluation of children from 2 to 12 years of age. It is considered the most used instrument for the evaluation of sexualized behavior in children (Everson \& Faller, 2012). Studies using the instrument found significant clinical levels of sexualized behavior in approximately $30-40 \%$ of the sample of sexually abused children, and observed significant differences between sexually abused children and those who had not experienced this (Friedrich, 2007).

\section{Instruments for the Children:}

Semi-Structured Interview with the Child: this interview was designed by the researchers and had the aim of establishing a bond with the child, investigating the experience of traumatic events, including situations of maltreatment, and exploring the most traumatic event. The interview was conducted according to the guidelines proposed by the Michigan protocol (Faller, 2003), consisting basically of: initial stage (rapport, establishment of basic interview rules, evaluation of the level of development of the child and whether the child can distinguish reality from fantasy and the truth from lies, and the general investigation of aspects of the life of the child); stage focused on the event (with the use of open questions, aiming to investigate the experience of traumatic events, stimulating the emission of the free report); and closing stage (the child is informed about the next steps, making oneself available, helping the child to restore balance, including the manifestation of feelings, thoughts and attitudes in relation to the revelation and the situation experienced).

$$
\text { Raven's Progressive Matrices Test }
$$
(Raven, Court, \& Raven, 1995), General Scale (Portuguese version by Angelini, Alves, Custódio, Duarte, \& Duarte, 1999), and Special Scale (Portuguese version by Angelini, Alves, Custódio, \& Duarte, 1987): this is a nonverbal test to assess the level of intelligence of individuals, with General (from 11 years) and Special (5-11 years) versions.

Trauma Symptom Checklist for Children (TSCC, Briere, 1996, Brazilian version by Lobo, Brunnet, Ecker, Schaefer, Arteche, Gauer, et al., 2015): measures posttraumatic symptoms and 
associated psychological symptoms in children and adolescents between 8 and 16 years of age who have experienced traumatic events. This is a 54-item self-report scale that seeks to track feelings, thoughts and behaviors, in which the subject scores between 0 (never) and 4 (all the time) in a comprehensive list of posttraumatic symptoms. It has two scales of validity (underresponse and hyper-response), six clinical scales (anxiety, depression, anger, posttraumatic stress, dissociation and sexual concerns) and eight critical items (Briere, 1996) that assess aspects that require immediate clinical attention. For all the clinical scales, with the exception of the Sexual Concerns scale, $T$ scores equal to or above 65 are considered clinically significant, and between 60 and 65 suggest significant subclinical symptomatology. For the Sexual Concern Scale, $T$ scores equal to or above 70 are considered clinically significant.

Child Post-Traumatic Cognitions Inventory (CPTCI; Meiser-Stedman et al., 2009, Brazilian version by Lobo, Brunnet, Ecker, Schaefer, Arteche, Gauer, et al., 2015): is a self-report scale composed of 25 items, aiming to measure negative posttraumatic cognitions in children and adolescents between the ages of 6 and 18, on a Likert type scale between 1 (don't agree at all) and 4 (agree a lot). It has two components: disturbing and permanent change after the trauma and feeble person in a scary world.

\section{Ethical and Data Collection Procedures}

The present study was approved by the Research Ethics Committee of the Pontifical Catholic University of Rio Grande do Sul (PUCRS), under authorization No. 247.127. The consent form was signed by all legal guardians of the children and the terms of assent by all the children who participated in the study, as established in Resolution No. 466/2012 of the National Health Council (2013). Data were collected in two sessions of approximately 1 hour each with the parents and two sessions of approximately 1 hour each with the children. The cases in which the need for medical and/ or psychological intervention was verified were referred to services of reference and the cases in which there was an evaluation of a current risk of exposure to maltreatment were reported to the authorities responsible.

\section{Data Analysis Procedures}

Sociodemographic and clinical variables were described through measures of central tendency and variability. The frequencies of the variables were observed, according to the cut-off points established in the instruments. Intra-group differences in the gender variable were analyzed using the chi-squared test, as well as analyses of differences between the genders in the general sample, using the Mann-Whitney $U$ test for the following variables: posttraumatic cognitions, sexualized behaviors, internalizing symptoms, externalizing symptoms, posttraumatic stress, anxiety, depression, anger, dissociation and sexual concerns. Analyses of differences between groups were also performed, using the Kruskal Wallis test, for the eight critical items of the TSCC and for the nine CSBI domains.

In order to identify the factors that differentiated the groups, a multinomial logistic regression analysis was performed. Multicollinearity tests were performed and all the variables included in the model presented Variance Influence Factors (VIFs) $<5$, indicating the absence of severe cases of multicollinearity. The dependent variable was the group: Sexual Abuse, Maltreatment without history of sexual abuse and Clinical Symptoms without a history of traumatic events. The Sexual abuse group was used as the reference. The independent variables included were: sexualized behaviors, posttraumatic cognitions, posttraumatic stress symptoms, depression, anxiety and dissociation, anger and sexual concerns. Due to the characteristics of the sample, non-parametric tests were used. The level of significance used was $5 \%$. The data from the instrument were computed and analyzed in the Statistical Package for the Social Sciences (SPSS) for Windows, version 17.0.

\section{Results}

From the analysis of the general sample, through the chi-squared test, statistically signifi- 
cant differences were observed in relation to the percentage of boys and girls in the sample, with a higher prevalence of females $\left[\chi^{2}(1)=5.58 ; p\right.$ $=.018]$. From the results of the Mann-Whitney $\mathrm{U}$ test, statistically significant differences were found in the general sample only with regard to the externalizing symptoms variable $[\mathrm{Z}(79)=$ -2.98; $p=.003$ ], with higher scores among the boys. In the intragroup analysis, through the chisquared test, the gender variable presented a statistically significant difference only in the sexual abuse group, with a higher prevalence of girls $\left[\chi^{2}(1)=9.53 ; p=.002\right]$.

Specifically regarding the Sexual abuse group, among the valid cases, $43.7 \%(n=14)$ of the children experienced a single episode and $56.3 \%(n=18)$ experienced recurrent episodes of sexual abuse. In addition, in $38.2 \%(n=13)$ of the cases, the episodes were perpetrated by a member of the nuclear family (mother/stepmother, father/stepfather, siblings $), 44.1 \%(n=15)$ by a member of the extended family (grandparents, uncles, cousins, friends and close neighbors), $14.7 \%(n=5)$ by a person known but not close, and in only one case $(2.9 \%)$ the perpetrator was unknown to the victim. Regarding the gender of the perpetrator, in $94.1 \%(n=32)$ of the cases the perpetrator was male and in $5.9 \%(n=3)$ of the cases, the episodes were perpetrated by men and women together. In $94.1 \%$ of the cases $(n$ $=32$ ), there was some kind of physical contact (touches, caresses or sexual intercourse) and in $5.9 \%(n=2)$ there was no physical contact (genital presentation or exposure to pornographic material). In $8.8 \%$ of the cases $(n=3)$ the result of the forensic physical assessment was positive. In $71.4 \%(n=15)$ of the occurrences there was a threat and $28.6 \%(n=6)$ of the cases were characterized by nonviolent persuasion. Finally, in $75.8 \%(n=25)$ of the cases, the last episode of sexual abuse occurred less than a year prior the moment of data collection.

Differences between groups were analyzed using the Kruskal Wallis test, for the eight critical items of the TSCC and for the nine domains of the CSBI (Table 1).

In order to identify the factors that differentiated the groups, a multinomial logistic regres- sion analysis was performed. The following variables: sexualized behaviors, anxiety, depression, anger, posttraumatic stress, dissociation, sexual concerns, posttraumatic cognitions, externalizing symptoms and internalizing symptoms. The results are shown in Table 2. The Sexual abuse group was used as the reference.

As can be seen, the Sexual concerns variable (TSCC) was the only one that was significant to differentiate the Sexual abuse group from both the Maltreatment without a history of sexual abuse group and the Clinical symptoms without a history of traumatic events group. From the results, it can be verified that the participants in the Maltreatment group were $8 \%$ less likely to have sexual concerns than the Sexual abuse group, whereas the Clinical symptoms group was $20 \%$ less likely to have sexual concerns than the Sexual abuse group. When the Sexual concerns variable was used to classify the groups, the percentage of correctly identified cases was $73.5 \%$ ( 25 out of 34 cases) in the Sexual abuse group, $28.6 \%$ (4 out of 14 cases) in the Maltreatment group, and $83.9 \%$ (26 out of 31 cases) in the Clinical symptoms group. The model presented general predictive ability to correctly classify $69.6 \%$ of the cases.

\section{Discussion}

The general aim of the study was to evaluate psychological and behavioral indicators in the forensic assessment of children with suspected sexual abuse. From the results, it can be observed that the factor that significantly differentiated the Sexual abuse group from the other groups was the Sexual concerns variable. The other variables of depression, anxiety, posttraumatic stress, dissociation, posttraumatic cognitions, anger and sexualized behaviors, as well as the internalizing and externalizing global symptomatology variables were not discriminant in the differentiation of the groups. In order to understand the analyses, it is important to reiterate that, in general, the CBCL evaluates internalizing symptoms (sum of the scales of anxiety/depression, isolation/depression, somatic complaints, social problems, thinking 
Table 1

Difference between Groups in the Critical Items of the TSCC and in the Domains of the CSBI

\begin{tabular}{|c|c|c|c|c|}
\hline & \multicolumn{3}{|c|}{ Mean $(S D)$} & \multirow[b]{2}{*}{$X^{2}$} \\
\hline & $\begin{array}{l}\text { Maltreatment } \\
\quad(n=14)\end{array}$ & $\begin{array}{l}\text { Sexual abuse } \\
\quad(n=34)\end{array}$ & $\begin{array}{l}\text { Clinical symptoms } \\
\qquad(n=31)\end{array}$ & \\
\hline \multicolumn{5}{|l|}{ TSCC critical items } \\
\hline Fear of men & $0.79(0.80)$ & $0.73(0.79)$ & $0.32(0.70)$ & $7.96^{*}$ \\
\hline Fear of women & $0.57(1.02)$ & $0.21(0.41)$ & $0.13(0.34)$ & 2.28 \\
\hline Want to hurt other people & $0.50(0.94)$ & $0.41(0.56)$ & $0.52(0.89)$ & 0.10 \\
\hline Want to hurt myself & $0.50(0.52)$ & $0.23(0.43)$ & $0.32(0.54)$ & 3.16 \\
\hline Start fights & $1.29(1.27)$ & $0.65(0.73)$ & $0.58(0.76)$ & 3.49 \\
\hline Fear that someone is going to kill me & $0.86(1.10)$ & $0.68(1.04)$ & $0.71(0.97)$ & 0.49 \\
\hline Want to kill myself & $0.36(0.84)$ & $0.15(0.36)$ & $0.16(0.37)$ & 0.44 \\
\hline $\begin{array}{l}\text { Do not trust people because they may } \\
\text { want to have sex }\end{array}$ & $0.57(1.09)$ & $1.03(1.14)$ & $0.10(0.30)$ & $16.47 * *$ \\
\hline \multicolumn{5}{|l|}{ CSBI Domains } \\
\hline Sexual intrusion & $0.29(0.61)$ & $0.38(0.74)$ & $0.03(0.18)$ & $6.72 *$ \\
\hline Sexual knowledge & $0.57(1.16)$ & $0.94(1.57)$ & $0.03(0.18)$ & $9.36^{*}$ \\
\hline Voyeuristic behavior & $1.5(1.99)$ & $0.71(1.36)$ & $0.16(0.45)$ & $7.23 *$ \\
\hline Interpersonal boundaries & $1.57(2.50)$ & $1.38(1.46)$ & $1.16(1.71)$ & 1.10 \\
\hline Sexual anxiety & $0.86(1.23)$ & $0.35(0.85)$ & $0.19(0.60)$ & 4.02 \\
\hline Exhibitionism & $0.14(0.53)$ & $0.06(0.24)$ & $0.13(0.56)$ & 0.04 \\
\hline Gender role behavior & $0.14(0.53)$ & $0.06(0.24)$ & $0.23(0.67)$ & 1.12 \\
\hline Self-stimulation & $0.14(0.53)$ & $0.24(0.85)$ & $0.77(1.71)$ & 3.37 \\
\hline Sexual interest & $0.64(0.74)$ & $0.68(1.27)$ & $0.45(0.99)$ & 2.48 \\
\hline
\end{tabular}

$* p<.05 ; * *<.001$

problems, attention problems) and externalizing symptoms (sum of the behavioral scales of rule breaking/delinquency and aggressive behavior), with scales specific for symptoms of depression, anxiety, posttraumatic stress, dissociation, sexual concerns and posttraumatic cognitions analyzed from the other instruments, which would be conceptualized as internalizing symptoms, and anger and sexualized behaviors scales, conceptualized as externalizing symptoms.

In relation to the descriptive analyzes, it was possible to verify that the majority of the children, both in the Sexual abuse group (50\%) and in the Maltreatment without a history of sexual abuse group (64.2\%), experienced other traumatic events throughout their lives, the most common being related to other situations of maltreatment. Polyvictimization (i.e. the experience of multiple traumatic events), seems to be a reality that affects many children, making it difficult to measure the effects of this exposure, overlapping possible symptoms and associated impairments (Guerra, Ocaranza, \& Weinberger, 2016; Hamby, Finkelhor, \& Turner, 2014).

Regarding the analysis of the differences between the sexes in the general sample, the only variable that presented a statistically significant 
Table 2

Multinominal Logistic Regression for the Maltreatment Group and the Clinical Symptoms Group compared to the Sexual Abuse Group

\begin{tabular}{lcccc}
\hline & \multicolumn{2}{c}{ Maltreatment } & \multicolumn{2}{c}{ Clinical symptoms } \\
\cline { 2 - 5 } & Odds ratio & $95 \%$ CI & Odds ratio & $95 \%$ CI \\
\hline Sexualized behaviors & 0.98 & $0.84-1.15$ & 0.91 & $0.785-1.06$ \\
Anxiety & 1.04 & $0.94-1.15$ & 1.06 & $0.97-1.15$ \\
Depression & 0.95 & $0.83-1.09$ & 1.06 & $0.93-1.22$ \\
Anger & 1.14 & $1.00-1.29$ & 1.04 & $0.93-1.18$ \\
Posttraumatic Stress & 1.00 & $0.91-1.12$ & 0.94 & $0.85-1.04$ \\
Dissociation & 1.04 & $0.92-1.16$ & 1.07 & $0.96-1.20$ \\
Sexual concerns & 0.92 & $0.84-1.00^{*}$ & 0.80 & $0.71-0.90^{* *}$ \\
Posttraumatic cognitions & 0.96 & $0.88-1.04$ & 0.94 & $0.88-1.01$ \\
Internalizing symptoms & 1.00 & $0.92-1.08$ & 1.01 & $0.93-1.09$ \\
Externalizing symptoms & 1.06 & $0.98-1.16$ & 1.03 & $0.96-1.09$
\end{tabular}

Note. Reference Group $=$ Sexual Abuse, $\chi^{2}(20)=46.63, p=.001$.

${ }^{*} p<.05, * * p<.001$.

difference was externalizing symptoms (when evaluated globally through the CBCL), with higher scores among the boys. These findings are corroborated by the literature, which shows, in general, that boys tend to present more externalizing symptoms than girls (Chaplin \& Aldao, 2013). Simultaneously, in the present study, no significant differences were found regarding internalizing symptoms. Previous studies have argued that although girls are more likely to be sexually abused than boys, victimization does not explain the increased risk for internalizing symptoms among girls, suggesting that gender and victimization should be considered as independent risk factors for internalizing symptoms (Ruiz, 2016). There were also no significant differences in posttraumatic symptoms between boys and girls, corroborating the findings of previous studies (Peixoto, 2012).

In relation to the general characteristics of the sample studied, the majority of the participants presented externalizing and internalizing symptoms in the clinical or borderline range, when these constructs were evaluated in a global way through the CBCL. On the other hand, considering the cut-off points established for the TSCC scales, the majority of the children in the three groups did not present significant symptomatology in any of the scales of this instrument. From these findings, one can discuss the fact that one of the instruments (CBCL) was answered by the guardians and the other (TSCC) by the children themselves. In view of this, especially in the forensic context, it is important to consider data from different information sources, with self-reported measures and reports by others, since both the guardians and the children themselves may not respond accurately to what is being investigated, sometimes under or overestimating symptoms.

The only group that presented a significant difference in the number of boys and girls was the Sexual abuse group, being constituted, for the most part, by females (76.5\%). This data is consistent with the literature, which indicates that girls suffer more sexual abuse, while boys experience more episodes of physical aggression (Asscher, van der Put, \& Stams, 2015). It is estimated that while one in five girls are victims of sexual abuse, one in 20 boys suffer from this type of violence (National Center for Victims of Crime, 2017). 
Regarding the characteristics of the Sexual abuse group, the results of the present study indicate that more than half of the children experienced recurrent episodes $(56.3 \%)$, most of them perpetrated by family members $(82.3 \%)$, of the male sex $(94.1 \%)$. These findings are corroborated by the literature, which highlights that approximately $80 \%$ of cases of sexual abuse are perpetrated by people close to the victim (Advocacy Center, 2014) and by the male sex (National Center for Posttraumatic Stress Disorder, 2014). In the majority of the cases of the present study, there was some type of physical contact $(94.1 \%)$, with the use of threats $(71.4 \%)$. However, the minority of the cases presented a positive result in the forensic physical assessment $(8.8 \%)$. This information is consistent with studies that highlight that the majority of the allegations of sexual abuse against children do not leave physical injuries (Joki-Erkkila et al., 2014). In addition, when the tests are positive, this evidence results, in most cases, from situations in which there was sexual intercourse or when violence was practiced with the use of physical force, which is more frequent in cases of extra-familiar violence.

Furthermore, the Sexual abuse group was the group that presented the highest scores in item 34 of the TSCC that evaluates "not being able to trust people because they may want to have sex", with significant differences being observed for this variable in relation to the other groups. To date, no studies have been found that have evaluated the discriminative ability of this variable among child victims of sexual abuse, although it has been emphasized that this item should be a focus of clinical attention, and may indicate the occurrence of sexual abuse (Briere, 1996). Therefore, based on this finding, it is suggested that further studies are carried out to investigate the discriminative ability of this variable, considering that it may be a potential indicator of the occurrence of sexual abuse.

Regarding the discriminative ability of variables commonly associated in the literature with the sexual abuse hypothesis, in the present study the majority of these did not present statistical significance to differentiate the groups. For ex- ample, the posttraumatic stress symptom variable did not present a statistically significant difference among the groups, contrary to previous findings (Lanktree et al., 2008; Peixoto, 2012). In a study that investigated the presence of posttraumatic symptoms as a sensitive tool to gauge the credibility of allegations of sexual abuse, the only indicator that appeared to be capable of discriminating children with suspected sexual abuse from those without this suspicion was the posttraumatic stress variable, measured through the TSCC and the Trauma Symptom Checklist for Young Children (TSCYC; Peixoto, 2012). Similar results have also highlighted the TSCC Posttraumatic stress scale as sensitive to distinguish child victims of sexual abuse from those who had not been through this experience (Lanktree et al., 2008). One of the hypotheses for the reason the Posttraumatic stress symptoms variable did not present a statistically significant difference in the present study is that the children victims of sexual abuse were compared with a group of children who had also been through other traumatic events, specifically, other maltreatment.

Regarding the Sexualized behaviors variable, studies have indicated the importance of evaluating the presence of sexualized behaviors that are inappropriate for the level of development in sexually abused children, as these indicators are supposed to be typical manifestations of this type of violence (Friedrich et al., 2001; Friedrich et al., 1997; Kendall-Tackett et al., 1993). According to a CSBI standardization study, the instrument is sensitive to measuring the effects of sexual abuse, although the authors themselves pointed out that sexualized behaviors can also be found in other cases where the child was not sexually abused, such as when exposed to stressful life events or presenting psychiatric diagnoses (Friedrich et al., 2001; Friedrich et al., 1992). Although the presence of sexualized behaviors is commonly associated with sexual abuse in children, in the present study this variable did not present statistical significance to discriminate the groups. In addition, sexualized behaviors, as well as being identified in children in the Sexual abuse group $(M=4.74)$, were also identified in children belonging to both the 
Clinical symptoms group $(M=3.13)$ and the Maltreatment group $(M=5.86)$, with the highest scores in the latter group. Previous studies have also found no statistically significant differences in this variable (Drach, Wientzen, \& Ricci, 2001; Peixoto, 2012). For example, in a study conducted from CSBI total scale scores, it was not possible to discriminate sexually abused children from those who had not been through this experiment, showing that to conclude the occurrence of sexual abuse from the presence of inappropriate sexualized behaviors may be misguided (Drach et al., 2001).

At the same time, when analyses of differences between the groups in the nine CSBI domains were conducted, statistically significant differences were observed in Sexual intrusion and in Sexual knowledge, both with higher scores in the Sexual abuse group, followed by the Maltreatment group with no history of sexual abuse, and in Voyeuristic behavior, with higher scores in the Maltreatment group without a history of sexual abuse, followed by the Sexual abuse group. In relation to this, authors have stressed that sexual abuse is more related to inadequate sexual knowledge than to problematic sexualized behavior (Brilleslijper-Kater, Friedrich, \& Corwin, 2004). However, due to the sample size of the study, it was chosen to only include the total CSBI score in the regression model. Therefore, it is suggested that future studies take into account the individual analysis of each domain of the instrument, considering that sexual abuse may be more directly related to specific domains and not necessarily problematic sexualized behaviors in general.

Sexualized behaviors that are inappropriate for the developmental level of the child have a very broad spectrum and can assume different manifestations, such as through exhibitionism, frequent and public masturbatory behaviors, sexual knowledge and interest advanced for the age, efforts to observe or touch the genitals of other people and seductive behavior, among others (Friedrich et al., 1997). Such behaviors may or may not be present in child victims of sexual abuse and differ in both the intensity and type of symptoms observed (Hall, Mathews, \& Pearce,
2002). In addition, this heterogeneity can be justified by the particularities intrinsic to the dynamics of sexual abuse and/or additional circumstances (Friedrich et al., 2001). It should also be noted that inappropriate sexualized behaviors are also observed in children with no history of sexual abuse, such as those who experienced physical, emotional or domestic abuse (Chaffin et al., 2008; Friedrich, 2007). This was also found as a result of the present study, in which the children in the Maltreatment group presented a higher mean in the CSBI total score $(M=$ $5.86)$ than in the Sexual abuse group $(M=4.74)$, as previously mentioned. Although the present study found no differences between the groups regarding sexualized behaviors among children aged 8 to 12 years, it should be emphasized that studies suggest that the highest scores in this variable appear in younger children (Friedrich et al., 2001; Peixoto, 2012). In addition, considering that the instrument is answered by the caregivers themselves, in some cases they may not be able to accurately describe the actual situation of the child, either under or overestimating symptoms (Friedrich et al., 2007).

In the present study, the Sexual concerns variable was the only one that presented statistical significance to differentiate the sexually abused children from the other groups. The model presented the general ability to correctly classify $69.6 \%$ of the cases. Elevated scores in this scale have already been reported as suggestive of sexual abuse (Briere, 1996). However, in the study conducted by Peixoto (2012), in which, as previously mentioned, one of the aims was to evaluate the presence of posttraumatic symptoms as a sensitive tool to gauge the credibility of allegations of sexual abuse, the Sexual concerns variable was not statistically significant to differentiate the child victims of sexual abuse from the group without this experience. No other study with these objectives was found to corroborate the finding encountered in the present study. Despite this, the result indicates that this variable can be measured in cases of suspected sexual abuse. In addition, the scores of this scale are obtained from the answers provided by the child, as 
opposed to the Sexualized behaviors variable measured by the CSBI.

Finally, it is important to note that the children who scored above the cutoff point of the TSCC standardization study for under and overestimation of symptoms were excluded from the analyses. These scales of validity are a differential of the instrument, especially in the forensic context, where there is a greater concern with the accuracy and validity of the information received.

One of the limitations in assessing the symptomatology triggered after the episode(s) of sexual abuse is the great variability between the time elapsed between the last episode of sexual abuse and the moment of the evaluation, as children often end up revealing the episodes later. This was also observed in the present sample, since in $24.2 \%(n=9)$ of the victims of sexual abuse, the last episode possibly occurred more than one year from the data collection moment. The lack of accuracy in the information provided by the participants themselves made it difficult to control this variable, since in some cases neither the child nor his/her caregiver was able to specify the period of the occurrence of the sexual abuse episode(s) and other maltreatment.

Regarding the analysis of the general sample, it should be noted that there was a significant difference in the total sample regarding the distribution of boys and girls, with a higher prevalence of females. Thus, a sample composed of more male participants would provide greater confidence regarding the presence or absence of significant differences between the genders in the clinical manifestation, as studies report that the age and gender of the victim impact on the symptomatological condition resulting from the abuse (Hébert, Lavoie, \& Blais, 2014; Ruiz, 2016).

\section{Final Considerations}

One of the main contributions of this study was to investigate psychological and behavioral indicators as possible discriminators between child victims of sexual abuse and children with- out any history of victimization, as well as considering children who have suffered other types of maltreatment. The variable Sexual concerns presented good discriminative ability in this sample, suggesting that high scores in this scale may reinforce the hypothesis of sexual abuse (Briere, 1996). Based on this finding, it is recommended that this variable be included, among other indicators, in the forensic examination procedures for children with this suspicion. In addition, it is suggested that other variables, such as the critical items of the TSCC and the different CSBI domains could be better investigated in future studies, as they can be configured as potential indicators of sexual abuse or reveal some specific situation that should be the focus of or require further investigation.

Although some particularities are observed in the manifestation of the symptomatology of child victims of sexual abuse in comparison with victims of other types of maltreatment, researchers reinforce that the chronicity, severity and circumstances of the event are more important than the type of maltreatment experienced (Jonkman, Verlinden, Bolle, Boer, \& Lindauer, 2013). It is important to take this information into account, especially in the forensic context, because when it comes to sexual abuse it must be made clear that it is a traumatic event, the nature of which varies across a continuum of severity and the experiences of children may be completely different, consequently influencing the impact of the event for each of them (Schaefer, Lobo, Brunnet, \& Kristensen, 2016).

In general, the results obtained indicate the need for caution in the establishment of causal associations between behavioral or psychological changes and the hypothesis of sexual abuse in children. Due to the great complexity and variability among cases of sexual abuse, there is no single symptomatological condition and therefore, confirming this type of occurrence with a single indicator or unreliable indicators is a big mistake (Peixoto, 2012). At the same time, the lack of a symptomatological condition also does not exclude the suspicion of sexual abuse, as the presence of symptoms may be due to other 
types of maltreatment or even a reaction to the context of the denunciation itself and the consequent judicial process, regardless of the veracity of the allegations (Peixoto, 2012).

Measuring the impact of the trauma and other associated variables can be useful in estimating the impairments triggered and corroborating other evidence, increasing the credibility of the evaluation (Everson \& Faller, 2012). However, such indicators should always be interpreted within the context of evaluation and be complementary to the forensic interview and should never be used in isolation to validate a case of suspected sexual abuse.

In the forensic assessment practice, the examiners must base their conclusions on information that can be scientifically supported (Ribeiro \& Peixoto, 2013). In this context, establishing the causal link between the alleged situation and the symptomatology manifested is an important and difficult task, as without the report of the child or other physical and/or biological evidence nothing can be affirmed regarding the occurrence or not of the abusive situation (Peixoto, 2012; Peixoto et al., 2017; Pelisoli et al., 2016). Therefore, it is fundamental to consider alternative hypotheses for the symptomatology and to investigate other possible events in the life history and development of the child (Schaefer et al., 2012).

Especially in the forensic context, it is essential to develop a battery of valid instruments that includes data from different sources of information, so that the findings can be compared. Furthermore, in view of the probative value of the report of the child for the forensic examination and the consequent judicial outcome, efforts should continue to be employed in training professionals and in the adaptation of forensic interview protocols valid for this context and for this population. In this way, professionals will be able to effectively adhere to good practice recommendations in the investigation of sexual abuse (Williams, Hackbarth, Aznar-Blefari, Padilha, \& Peixoto, 2014). From this set of indicators, it becomes possible to support the forensic conclusions with more confidence and assertiveness.

\section{Authors' Contributions}

Substantial contribution in the concept and design of the study: Luiziana Souto Schaefer; Christian Haag Kristensen.

Contribution to data collection: Luiziana Souto Schaefer; Alice Einloft Brunnet; Beatriz de Oliveira Meneguelo Lobo; Janaína Núñez Carvalho.

Contribution to data analysis and interpretation: Luiziana Souto Schaefer; Alice Einloft Brunnet; Janaína Núñez Carvalho; Christian Haag Kristensen.

Contribution to manuscript preparation: $\mathrm{Lu}-$ iziana Souto Schaefer; Alice Einloft Brunnet; Beatriz de Oliveira Meneguelo Lobo.

Contribution to critical revision, adding intelectual content: Luiziana Souto Schaefer; Alice Einloft Brunnet; Beatriz de Oliveira Meneguelo Lobo; Janaína Núñez Carvalho; Christian Haag Kristensen.

\section{Conflicts of interest}

The authors declare that they have no conflict of interest related to the publication of this manuscript.

\section{References}

Achenbach, T. M. (1991). Manual for the child behavior checklist/418 and 1991 profile. Burlington, VT: University of Vermont.

Achenbach, T. M. (2001). Manual for the child behavior checklist/618 and 2001 profile. Burlington, VT: University of Vermont.

Advocacy Center (2014). Child sexual abuse. Retrieved from http://www.theadvocacycenter. org/adv abusewho.html

American Psychiatric Association. (2014). Diagnostic and statistical manual of mental disorders ( $5^{\text {th }}$ ed.). Washington, DC: Author.

Angelini, A. L., Alves, I. C. B., Custódio, E. M., \& Duarte, W. (1987). Manual das matrizes progressivas coloridas. São Paulo, SP: Casa do Psicólogo.

Angelini, A. L., Alves, I. C. B., Custódio, E. M., Duarte, W. F., \& Duarte, J. L. M. (1999). 
Matrizes progressivas coloridas de Raven: Escala especial. São Paulo, SP: Centro Editor de Testes e Pesquisa em Psicologia.

Asscher, J. J., van der Put, C. E., \& Stams, G. J. J. (2015). Gender Differences in the Impact of Abuse and Neglect Victimization on Adolescent Offending Behavior. Journal of Family Violence, 30(2), 215-225. doi: 10.1007/s10896014-9668-4

Bordin, I. A. S., Mari, J. J., \& Caeiro, M. F. (1995). Validação da versão brasileira do Child Behaviour Checklist (CBCL) (Inventário de Comportamento da Infância e da Adolescência): Dados preliminares. Revista da ABP, 17(2), 55-66. doi: 10.2471/BLT.07.043125

Brazilian Association of Research Companies. (2015). Critério de Classificação Econômica Brasil. Retrieved from http://www.abep.org/ codigos-e-guias-da-abep

Briere, J. (1996). Trauma Symptom Checklist for Children (TSCC) professional manual. Odessa, FL: Psychological Assessment Resources.

Brilleslijper-Kater, S. N., Friedrich, W. N., \& Corwin, D. L. (2004). Sexual knowledge and emotional reaction as indicators of sexual abuse in young children: Theory and research challenges. Child Abuse \& Neglect, 28(10), 1007-1017. doi: 10.1016/j.chiabu.2004.06.005

Chaffin, M., Berliner, L., Block, R., Johnson, T. C., Friedrich, W. N., Louis, D. G., \& Madden, C. (2008). Report of the ATSA task force on children with sexual behavior problems. Child Maltreatment, 13(2), 199-218. doi: 10.1177/1077559507306718

Chaplin, T. M., \& Aldao, A. (2013). Gender differences in emotion expression in children: A meta-analytic review. Psychological Bulletin, 139(4), 735-765. doi: 10.1037/a0030737

Collin-Vézina, D., Daigneault, I., \& Hébert, M. (2013). Lessons learned from child sexual abuse research: Prevalence, outcomes, and preventive strategies. Child and Adolescent Psychiatry and Mental Health, 7-22. doi: 10.1186/1753-2000$7-22$

Drach, K. M., Wientzen, J., \& Ricci, L. R. (2001). The diagnostic utility of sexual behavior problems in diagnosing sexual abuse in a forensic child abuse evaluation clinic. Child Abuse \& Neglect, 25(4), 489-503. doi: 10.1016/ S0145-2134(01)00222-8
Everson, M. D., \& Faller, K. C. (2012). Base rates, multiple indicators, and comprehensive forensic evaluations: Why sexualized behavior still counts in assessments of child sexual abuse allegations. Journal of Child Sexual Abuse, 21, 45-71. doi: 10.1080/10538712.2012.642470

Faller, K. C. (2003). Understanding and assessing child sexual maltreatment ( $2^{\text {th }}$ ed.). Thousand Oaks, CA: Sage.

Friedrich, W. N. (2007). Children with sexual behavior problems. New York: W.W. Norton.

Friedrich, W. N., Fisher, J. L., Dittner, C. A., Acton, R., Berliner, L., Butler, J., \& Wright, J. (2001). Child sexual behavior inventory: Normative, psychiatric, and sexual abuse comparisons. Child Maltreatment, 6(1), 37-49. doi: $10.1177 / 1077559501006001004$

Friedrich, W. N., Grambsch, P., Damon, L., Hewitt, S. K., Koverola, C., Lang, R. A., ...Broughton, D. (1992). Child sexual behavior inventory: Normative and clinical comparisons. Psychological Assessment, 4(3), 303-311. doi: $10.1177 / 1077559501006001004$

Friedrich, W. N., Jaworski, T. M., Huxsahl, J., \& Bengtson, B. (1997). Dissociative and sexual behaviors in children and adolescents with sexual abuse and psychiatric histories. Journal of Interpersonal Violence, 12, 155-171. doi: 10.1177/088626097012002001

Gava, L. L., Pelisoli, C., \& Dell'Aglio, D. D. (2013). A perícia psicológica em casos de suspeita de abuso sexual infanto-juvenil. Avaliação Psicológica, 12(2), 137-145. Retrieved from http://pepsic.bvsalud.org/pdf/avp/v12n2/ v12n2a05.pdf

Guerra, C., Ocaranza, C., \& Weinberger, K. (2016). Searching for social support moderates the relationship between polyvictimization and externalizing symptoms: A brief report. Journal of Interpersonal Violence. doi: $10.1177 / 0886260516642293$

Habigzang, L. F., Borges, J. L., Dell'Aglio, D. D., \& Koller, S. H. (2010). Caracterização dos sintomas do Transtorno de Estresse Pós-Traumático (TEPT) em meninas vítimas de abuso sexual. Psicologia Clínica, 22(2), 27-44. doi: 10.1590/ S0103-56652010000200003

Hall, D. K., Mathews, F., \& Pearce, J. (2002). Sexual behavior problems in sexually abused children: A preliminary typology. Child Abuse 
\& Neglect, 26(3), 289-312. doi: 10.1016/S01452134(01)00326-X

Hamby, S., Finkelhor, D., \& Turner, H. (2014). Origine et développement du concept de polyvictimisation. Criminologie, 47(1), 11-15. doi: $10.7202 / 1024004$

Hébert, M., Lavoie, F., \& Blais, M. (2014). Post Traumatic Stress Disorder/PTSD in adolescent victims of sexual abuse: Resilience and social support as protection factors. Ciênc. saúde coletiva, 19(3), 685-694. doi: 10.1590/141381232014193.15972013

Irigaray, T. Q., Fonseca, R. P., Pacheco, J., Leite, J. C. C., Grassi-Oliveira, R., \& Kristensen, C. H. (2013). Child maltreatment and later cognitive functioning: A systematic review. Psicologia: Reflexão \& Crítica, 26(2), 376-387. doi: 10.1590/S0102-79722013000200018

Joki-Erkkila, M., Niemi, J., \& Ellonen, N. (2014). Child sexual abuse - Medical statement conclusions in criminal legal process. Forensic Science International, 239, 31-26. doi: 10.1016/j. forsciint.2014.03.006

Jonkman, C. S., Verlinden, E., Bolle, E. A., Boer, F., \& Lindauer, J. L. (2013). Traumatic stress symptomatology after child maltreatment and single traumatic events: Different profiles. Journal of Traumatic Stress, 26(2), 225-32. doi: 10.1002/ jts.21792

Kendall-Tackett, K. A., Williams, L. M., \& Finkelhor, D. (1993). Impact of sexual abuse on children: A review and synthesis of recent empirical studies. Psychological Bulletin, 113(1), 164-180. doi: 10.1037/0033-2909.113.1.164

Lanktree, C. B., Gilbert, A. M., Briere, J., Taylor, N., Chen, K., Maida, C. A., \& Saltzman, W. R. (2008). Multi-informant assessment of maltreated children: Convergent and discriminant validity of the TSCC and TSCYC. Child abuse \& neglect, 32(6), 621-625. doi: 10.1016/j.chiabu.2007.10.003

Lobo, B., Brunnet, A., Ecker, K., Schaefer, L., Arteche, A., Gauer, G., \& Kristensen, C. (2015). Psychometric properties of the child posttraumatic cognitions inventory in a sample of brazilian children. Journal of Aggression, Maltreatment and Trauma, 24(8), 863-875. http://doi.or g/10.1080/10926771.2015.1043065

Lobo, B., Brunnet, A., Ecker, K., Schaefer, L., Arteche, A., \& Kristensen, C. (2015). Cross-
Cultural Adaptation and Psychometric Properties of the Trauma Symptom Checklist for Children (TSCC) in a Sample of Brazilian Children: Preliminary Results. Journal of Child \& Adolescent Trauma. http://doi.org/10.1007/ s40653-0150044-1

Meiser-Stedman, R., Smith, P., Bryant, R., Salmon, K., Yule, W., Dalgleish, T., \& Nixon, R. D. V. (2009). Development and validation of the Child Post-Traumatic Cognitions Inventory (CPTCI). Journal of Child Psychology and Psychiatry, and Allied Disciplines, 50(4), 432-440. doi: 10.1111/j.1469-7610.2008.01995.x

Miele, A., \& Arteche, A. X. (2017). Tradução e Adaptação para o Português do Child Sexual Behavior Inventory. Manuscript in press.

National Center for Posttraumatic Stress Disorder. (2014). Child sexual abuse. Retrieved from http://www.ptsd.va.gov/public/types/violence/ child-sexual-abuse.asp

National Center for Victims of Crime. (2017). Child sexual abuse statistics. Retrieved from https:// victimsofcrime.org/media/reporting-on-childsexual-abuse/child-sexual-abuse-statistics

Paolucci, E. O., Genuis, M. L., \& Violato, C. (2001). A meta-analysis of the published research on the effects of child sexual abuse. The Journal of Psychology, 135, 17-36. doi: 10.1080/00223980109603677

Peixoto, C. E. (2012). Avaliação da credibilidade de alegações de abuso sexual de crianças: Uma perspetiva psicológica forense (Doctoral dissertation, Universidade do Porto, Portugal).

Peixoto, C. E., Fernandes, R. V., Almeida, T. S., Silva, J. M., La Rooy, D., Ribeiro, C., ...Lamb, M. E. (2017). Interviews of Children in a Portuguese Special Judicial Procedure. Behavioral Sciences \& the Law, 35(3), 189-203. doi: $10.1002 / b s l .2284$

Pelisoli, C. L., Dell'Aglio, D. D., \& Herman, S. (2016). Sete erros na avaliação de abuso sexual contra crianças e adolescentes. In S. J. L. Vasconcelos \& V. de M. Lago (Eds.), A psicologia jurídica e as suas interfaces: Um panorama atual (pp. 127-146). Santa Maria, RS: Editora da Universidade Federal de Santa Maria.

Portal Governo do Brasil, Direitos Humanos. (2017). Dia nacional contra abuso sexual de crianças e jovens é celebrado nesta quinta. Retrieved 
from http://www.brasil.gov.br/cidadania-ejustica/2017/05/dia-nacional-contra-abusosexual-de-criancas-e-jovens-e-celebrado-nestaquinta-18

Raven, J. C., Court, J. H., \& Raven, J. (1995). Manual for Raven's Progressive Matrices and Vocabulary Scales. Oxford, UK: Oxford Psychologists Press.

Resolution No. 466/2012. (2013, June 13). Diário Oficial da União, p. 59.

Ribeiro, C., \& Peixoto, C. E. (2013). Avaliação psicológica forense de crianças alegadamente vítimas de abuso sexual. In T. Magalhães \& D. N. Vieira (Eds.), Abuso \& Negligência Série 2 - Agressões Sexuais: Intervenção Pericial Integrada (pp. 103-119). Maia, Portugal: Sociedade Portuguesa para o Estudo da Criança Abusada e Negligenciada.

Ruiz, E. (2016). Trauma symptoms in a diverse population of sexually abused children. Psychological Trauma: Theory, Research, Practice, and Policy, 8(6), 680-687. doi: $10.1037 / \operatorname{tra} 0000160$

Schaefer, L. S., Lobo, B. O. M., Brunnet, A. E., \& Kristensen, C. H. (2016). Reações póstraumáticas em crianças: Como, por que e quais aspectos avaliar? Interação em Psicologia, 20(1), 112123. doi: 10.5380/psi.v20i1.30294

Schaefer, L. S., Rossetto, S., \& Kristensen, C. H. (2012). Perícia Psicológica no abuso sexual de crianças e adolescentes. Psicologia: Teoria e Pesquisa, 28, 227-234. doi: 10.1590/S010237722012000200011
Stoltenborgh, M., van IJzendoorn, M. H., Euser, E. M., \& Bakermans-Kranenburg, M. J. (2011). A Global Perspective on Child Sexual Abuse: Meta-Analysis of Prevalence around the World. Child Maltreatment, 16(2), 79-101. doi: 10.1177/1077559511403920

Van den Heuvel, L., \& Seedat, S. (2013). Screening and diagnostic considerations in childhood posttraumatic stress disorder. Neuropsychiatry, 3(5), 497-511. doi: 10.2217/npy.13.61

Wherry, J. N., Baldwin, S., Junco, K., \& Floyd, B. (2013). Suicidal thoughts/behaviors in sexually abused children. Journal of Child Sexual Abuse, 22(5), 534-551. doi: $10.1080 / 10538712.2013 .800938$

Williams, L. C. de A., Hackbarth, C., Aznar-Blefari, C., Padilha, M. da G. S., \& Peixoto, C. E. (2014). Investigação de suspeita de abuso sexual infantojuvenil: O Protocolo NICHD. Temas em Psicologia, 22(2), 415-432. doi: 10.9788/ TP2014.2-12

World Health Organization. (2002). World report on violence and health. Geneva: Author.
Received: $12 / 07 / 2017$

$1^{\text {st }}$ revision: $16 / 08 / 2017$ Accepted: 26/08/2017

(c) BY (C) The Author(s), 2018. Open Access. This article is distributed under the terms of the Creative Commons Attribution 4.0 International License (http://creativecommons.org/licenses/by/4.0/), which permits unrestricted use, distribution, and reproduction in any medium, provided you give appropriate credit to the original author(s) and the source, provide a link to the Creative Commons license, and indicate if changes were made. 